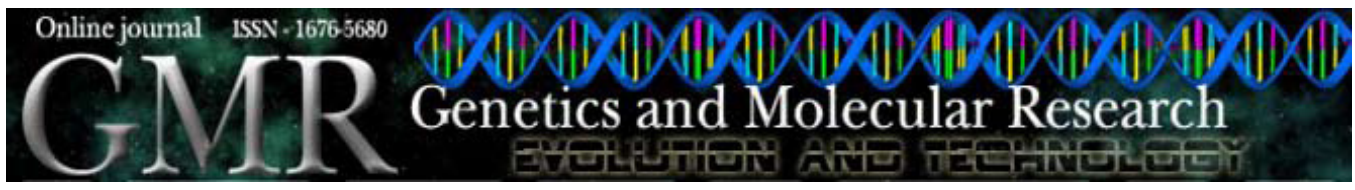

\title{
Molecular characterization of an expressed sequence tag representing the cuticle-degrading serine protease gene $(P I I)$ from the nematophagous fungus Arthrobotrys oviformis by differential display technology
}

\author{
A. Nagee ${ }^{1}$, A. Acharya ${ }^{2}$, A. Shete ${ }^{2}$, P.N. Mukhopadhyaya ${ }^{2,3}$ and B.A. Aich ${ }^{2}$ \\ ${ }^{1}$ Ashok and Rita Patel Institute of Integrated Study and Research in \\ Biotechnology and Allied Sciences, New Vallabh Vidyanagar, Anand, India \\ ${ }^{2}$ Medical Genetics Division, geneOmbio Technologies, Krishna Chambers, \\ Pashan-Sus Road, Pashan, Pune, Maharashtra, Gujarat, India
}

Corresponding author: P.N. Mukhopadhyaya

E-mail: pnm6619@yahoo.co.in

Genet. Mol. Res. 7 (4): 1200-1208 (2008)

Received June 27, 2008

Accepted August 11, 2008

Published November 4, 2008

\begin{abstract}
The technology of mRNA-based differential display reverse transcriptase-polymerase chain reaction (DDRT-PCR) was used to detect a 246-bp differentially expressed fragment from the nematophagous fungus Arthrobotrys oviformis when young mycelia were induced with the round worm Haemonchus contortus. The fragment was converted into an expressed sequence tag (EST) through characterization at the molecular level. Homology search indicated that the differentially expressed fragment originated from the cuticle-degrading serine protease gene, which has been previously reported to play a role in nematophagous activity in A. oligospora, Dactylaria parvispora, A. musiformis, and other potential anti-fungal biological control agents. Several single nucleotide polymorphisms found to represent both synonymous as well as non-synonymous mutations within this short sequence stretch of $246 \mathrm{bp}$ suggested genetic variability within the gene in this group of nematode-trapping fungi. The cloned EST fragment
\end{abstract}


has potential for use as a hybridization probe for searching full-length gene from an appropriate cDNA library of this and related fungi. This is the first report of the identification of an EST representing the cuticledegrading serine protease gene from $A$. oviformis using the technique of DDRT-PCR.

Key words: Expressed sequence tag; Biological control; Differential display reverse transcriptase; Nematophagous; Single nucleotide polymorphism

\section{INTRODUCTION}

Approaches other than chemotherapy for the control of nematode parasites in ruminants are becoming increasingly important in India because of rapidly developing anthelmintic resistance in parasitic nematodes of ruminants, increasing concern of chemical residues in livestock products and the environment in general (Sanyal, 1998). Biological control methods using nematophagous fungi could be one such step in this direction. Biological control is aimed at exploiting natural enemies to reduce the number of target organisms at a level less than what would have occurred in the absence of predators. Fungi that exhibit anti-nematode activity have been known for a long time. They produce specialized hyphal structures such as adhesive knobs, networks, constricted or non-constricted rings, and other such formations for trapping the worms (Barron, 1979).

Significant research has been underway for a long time to isolate new fungi and to determine their efficacy in worm control programs. This has, therefore, led to the isolation of a large number of fungal isolates belonging to the nematophagous group. Furthermore, a wide range of nematode-trapping activity has been demonstrated within these fungi. Delivery devices are also conceptualized from time to time to identify means for exploiting these organisms for nematode control in the field. The ability to resist gut passage of animals by the chlamydospores of some nematode-trapping fungi has provided a unique means for its dissemination (Gronvold et al., 1993). However, in this strategy, one has to rely on the isolation of a superior strain of fungus for equally superior biological control. For genetic improvement of these organisms, it is necessary to understand the molecular basis of biological control and to identify the different genetic components that play a role during the process of nematode predation. In order to address this issue, a work plan was undertaken to assist in the identification of genes that are selectively expressed during the process of predation of the worms.

All living organisms have tens of thousands of unique genes in their genomes of which perhaps $15 \%$ are expressed in any individual cell (Benjamin, 2004). Therefore, it is the temporal and spatial regulation of gene expression that determines life processes. The course of normal cellular development and activity as well as pathological and other specialized changes that arise during the process of a specific mode of nutrition or diseased condition are believed to be driven by changes in gene expression (Mankau, 1980).

One of the pressing problems has been to identify and characterize those genes that are differentially expressed in order to understand the molecular nature of the specialized activity (in our case, nematode predation) and subsequently isolate and identify them and their activity level. Differential display (DD), a technology discovered in 1992, allows rapid, accu- 
rate and sensitive detection of altered gene expression (Liang and Pardee, 1992). This technology works by systematic amplification of mRNA and resolution of those fragments on a DNA sequencing gel. Using anchored primers designed to bind to the 5' end of the poly-A tails for reverse transcription (RT), followed by polymerase chain reaction (PCR) amplification with additional upstream primers of arbitrary sequence, mRNA sub-populations are visualized by denaturing polyacrylamide gel electrophoresis. This allows direct side-by-side comparison of most of the mRNAs between or among related cells.

\section{MATERIAL AND METHODS}

\section{Growth of fungal mycelium and induction with Haemonchus contortus}

The fungi were grown in duplicate in liquid CMA medium (Minglian et al., 2004) using spore suspension as the inoculum. The culture was grown at $28^{\circ} \mathrm{C}$ under shaking conditions (200 rpm) for four days. This was followed by the addition of $1 \mathrm{~mL}$ Haemonchus contortus larval suspension (1000 larvae/mL in sterile phosphate buffer, $\mathrm{pH}$ 7) (Sanyal and Mukhopadhyaya, 2003) in one of the flask (induced) and an equal volume of sterile phosphate buffer in the other (uninduced) that served as control. Following induction (Sanyal et al., 2002), the cultures were further incubated under shaking conditions for another 2 days after which total mRNA was extracted from the mycelia.

\section{Extraction of total RNA}

Total RNA was extracted from freshly grown fungal mycelium (100 mg) with RNAzol (Gibco BRL Life Technologies, USA) as recommended by the manufacturer. RNA was digested with RNase-free DNase I (Promega Corporation, USA) for $30 \mathrm{~min}$ at $37^{\circ} \mathrm{C}$ in $50 \mathrm{mM}$ Tris buffer, $\mathrm{pH} 6.5$, with $10 \mathrm{mmol} / \mathrm{L} \mathrm{MgCl}_{2}$ and $10 \mathrm{mM}$ dithiothreitol. The reaction was terminated with $10 \mathrm{X}$ termination mix (0.1 M EDTA, $\mathrm{pH} 8.0$, and $1 \mathrm{mg} / \mathrm{mL}$ glycogen), and RNA was purified using the phenol method (Sambrook et al., 1989).

\section{Differential display of mRNA}

Total RNA was treated with amplification grade RNase-free DNase I (BRL) at $37^{\circ} \mathrm{C}$ for 30 min to remove possible DNA contamination. The RNA concentration was calculated from the absorbance at $260 \mathrm{~nm}$. The DD procedure recommended by the manufacturer (GenHunter Corporation, USA) was followed. For first-strand cDNA synthesis, a $19-\mu \mathrm{L}$ mixture containing $0.5 \mu \mathrm{g}$ total RNA, 4 pmol oligo(dT) primer 5'-HT11M-3' (where M may be G, A, orC), 400 pmol deoxynucleoside triphosphate, $25 \mathrm{mM}$ Tris- $\mathrm{HCl}$, $\mathrm{pH} \mathrm{8.3,37.6 \textrm {mM } \mathrm { KCl } , 1 . 5 \mathrm { mM } \mathrm { MgCl }}$, and $5 \mathrm{mM}$ dithiothreitol was heated at $65^{\circ} \mathrm{C}$ for $5 \mathrm{~min}$. The temperature was then reduced to $37^{\circ} \mathrm{C}$, and after $10 \mathrm{~min}, 1 \mu \mathrm{L}$ Moloney murine leukemia virus RT (200 U) was added. The incubation was then continued at $37^{\circ} \mathrm{C}$ for another $50 \mathrm{~min}$. Finally, the $20-\mu \mathrm{L}$ reaction mixture was heated at $75^{\circ} \mathrm{C}$ for $5 \mathrm{~min}$ and then chilled to $4^{\circ} \mathrm{C}$. For PCR, $5 \mu \mathrm{L}$ first-strand cDNA solution was added to 100 pmol H-AP1 and H-T11G primers, each deoxynucleoside triphosphate at a final concentration of $200 \mu \mathrm{M}, 5 \mu \mathrm{Ci}$ of $\left.{ }^{32} \mathrm{P}\right]-\mathrm{dCTP}$, and 1 unit of Taq polymerase (Boehringer Mannheim) in buffer supplied by the manufacturer in a final reaction volume of $50 \mu \mathrm{L}$. 
The reaction was carried out in a programmable thermal controller (Geneamp PCR System 9700, Applied Biosystems, USA) as follows: $94^{\circ} \mathrm{C}$ for $30 \mathrm{~s}, 40^{\circ} \mathrm{C}$ for $2 \mathrm{~min}$, and $72^{\circ} \mathrm{C}$ for $30 \mathrm{~s}$ for 40 cycles. An additional final extension step was performed at $72^{\circ} \mathrm{C}$ for $5 \mathrm{~min}$. Each PCR product $(3.5 \mu \mathrm{L})$ was mixed with $2 \mu \mathrm{L}$ loading dye $(95 \%$ formamide, $10 \mathrm{mM}$ EDTA, $\mathrm{pH}$ $8.0,0.09 \%$ xylene cyanol FF, and $0.09 \%$ bromophenol blue) and incubated at $80^{\circ} \mathrm{C}$ for $2 \mathrm{~min}$ immediately before being loaded onto a $6 \%$ DNA sequencing gel. The gel was run at $60 \mathrm{~W}$ for $\sim 3 \mathrm{~h}$, placed on a piece of $3 \mathrm{M}$ paper, vacuum dried at $80^{\circ} \mathrm{C}$ for $1 \mathrm{~h}$, and exposed to X-ray film. For re-amplification of the cDNA probe, gel segments representing DNA bands of interest were cut out with razors. Each gel slice along with the $3 \mathrm{M}$ paper was soaked in $100 \mu \mathrm{L}$ water for $10 \mathrm{~min}$, and DNA was eluted by boiling for $15 \mathrm{~min}$ and precipitated with ethanol in the presence of $50 \mu \mathrm{g}$ glycogen as a carrier. To re-amplify the DNA fragments, $4 \mu \mathrm{L}$ of the total $10 \mu \mathrm{L}$ eluted DNA was mixed with $36 \mu \mathrm{L}$ of a reaction mixture containing $3 \mathrm{U}$ Taq DNA polymerase (BRL), $2.2 \mu \mathrm{M}$ dNTP, $0.22 \mu \mathrm{M}$ oligo(dT) primer 5'-T11M-3', $0.22 \mu \mathrm{M}$ arbitrary decanucleotide primer, $11.1 \mu \mathrm{M}$ Tris- $\mathrm{HCl}, \mathrm{pH} 8.4,55.6 \mathrm{mM} \mathrm{KCl}, 1.67 \mathrm{mM} \mathrm{MgCl}_{2}$, and $0.001 \%$ gelatin. PCR conditions were the same as those described above. The DNA was then precipitated in ethanol and subsequently re-amplified using the conditions described above without the radioisotope. PCR products were then cloned in the HindIII site of the vector pGEMH3-2 (Nagee et al., 2008) using standard protocol (Sambrook et al., 1989).

\section{Northern blot analysis}

Northern blot analysis of the Arthrobotrys oviformis mRNA in nematode induced (+) and uninduced (-) growth media was performed as described below.

Total RNA was dissolved in a solution containing $50 \%$ formamide, $16 \%$ formaldehyde, $20 \mathrm{mM}$ MOPS [3-( $\mathrm{N}$-morpholino) propanesulfonic acid], $5 \mathrm{mM}$ sodium acetate, and $1 \mathrm{mM}$ EDTA, pH 7.0, incubated for $15 \mathrm{~min}$ at $65^{\circ} \mathrm{C}$, and chilled on ice. Denatured samples were subjected to electrophoresis on $1 \%$ agarose gels containing $2.2 \mathrm{M}$ formaldehyde and were blotted onto Nytran membranes. The blots were prehybridized for $\sim 4 \mathrm{~h}$ at $65^{\circ} \mathrm{C}$ in a solution containing 6X SSC (1X SSC is $0.15 \mathrm{M} \mathrm{NaCl}$ plus $0.015 \mathrm{M}$ sodium citrate, $\mathrm{pH} 7.6$ ), $2 \mathrm{X}$ Denhardt's solution, $0.1 \% \mathrm{SDS}$, and $100 \mu \mathrm{g}$ sheared salmon DNA $/ \mu \mathrm{L}$ and hybridized for $\sim 16 \mathrm{~h}$ in the same solution with $10^{6} \mathrm{cpm}$ of a ${ }^{32} \mathrm{P}$-labeled cDNA probe $/ \mathrm{mL}$ prepared by random prime labeling. The membranes were washed twice for $10 \mathrm{~min}$ at room temperature in $2 \mathrm{X}$ SSC plus $0.1 \%$ SDS, briefly washed at $65^{\circ} \mathrm{C}$ with $0.2 \mathrm{XSSC}$ plus $0.1 \% \mathrm{SDS}$, and exposed to X-ray film at $-80^{\circ} \mathrm{C}$ in the presence of an intensifying screen.

All reagents and fine chemicals used were of analytical grade unless otherwise mentioned.

\section{RESULTS AND DISCUSSION}

We isolated this strain of A. oviformis in the year 2001 from the western part of India and demonstrated its nematode-trapping activity. This study established its candidature as a potent biological control agent for round worms infesting the gut of grazing animals (Nagee et al., 2001). Recently, a protocol for producing protoplasts in this fungus was published by our group, which paved the way towards establishing a sound gene delivery system for this economically important organism (Nagee and Mukhopadhyaya, 2007). The present study was 
initiated to identify genes involved in nematode-trapping activity with the long-term goal of developing a genetically modified fungus with an improved nematophagous property.

Studies indicate that differential expression of genes occurs when nematode-trapping fungi are induced with nematodes (Tunlid and Jansson, 1991; Ahman et al., 1996). Based on such observations, this study was initiated with two objectives. First, to establish differential expression of genes in our isolate of A. oviformis and then to generate an expressed sequence tag (EST) that can be used for probing a genomic library for identifying the full-length gene sequence.

The technique of DDRT-PCR is unique in its potential to visualize expressed genes in eukaryotic cells in a systematic, non-biased and sequence-dependent manner using multipleprimer combinations. More importantly the method enables the recovery of sequence information and the development of probes to isolate their cDNA and genomic DNA for further molecular and functional characterization. Because of its simplicity, sensitivity and reproducibility, the mRNA DD technology is finding wide-ranging and rapid application in developmental biology, cancer research, neuroscience pathology, endocrinology, and plant physiology (Liu and Kolattukudy, 1998).

Of the three uptake sequence primers used for cDNA synthesis, viz., H-T11A, H-T11G and H-T11C, H-T11G in conjunction with $\mathrm{H}-\mathrm{AP} 1$ random primer generated a well-resolved, differential profile. Other primer combinations comprising any of the other uptake sequence primers (H-T11A or H-T11C) used for cDNA synthesis and H-AP2-H-AP8 random primers for generating radio-labeled amplicons either yielded too many fragments that compromised with resolution or failed to generate differentially expressed ones.

A 246-bp fragment was found to be consistently present in the induced sample and absent in the uninduced counterpart (Figure 1). This was eluted and re-amplified to generate a distinct PCR amplicon (Figure 2). This amplicon was then digested with HindIII and cloned in the HindIII site of the vector pGEMH3-2 (Nagee et al., 2008) to generate pGEMH3-2SP. The insert within the recombinant plasmid pGEMH3-2SP was sequenced with the Big Dye Terminator version 3.1 cycle sequencing kit (Applied Biosystems, USA) and resolved on a Genetic Analyzer 3130 (Applied Biosystems, USA). The sequence thus obtained was submitted to Genbank (USA) and was assigned the accession No. AY207006.

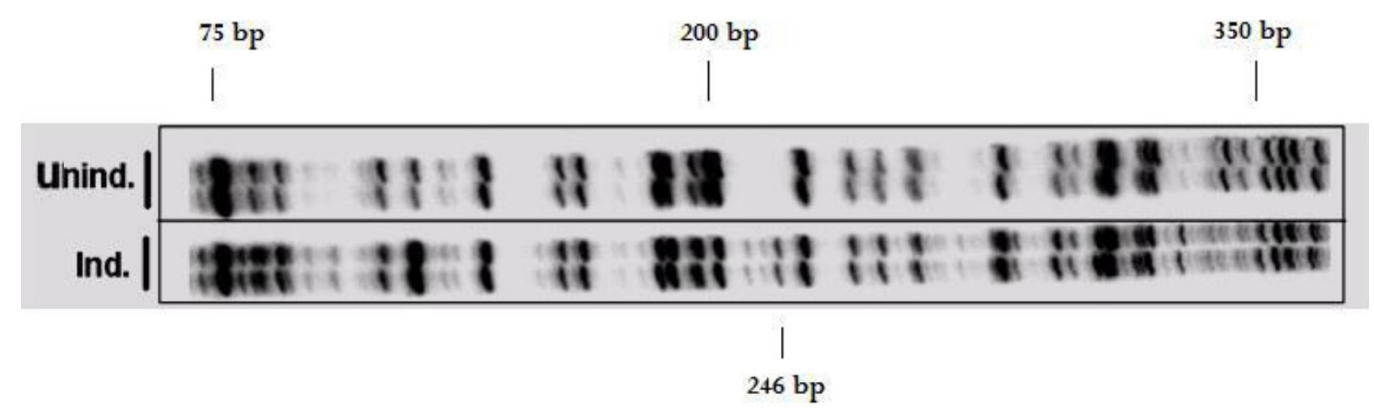

Figure 1. Differential display reverse transcriptase-polymerase chain reaction (DDRT-PCR) profile from induced and uninduced Arthrobotrys oviformis mycelia using H-T11G for cDNA synthesis and H-AP1 as the random primer. Unind., uninduced; Ind., induced with Haemonchus contortus. The 246-bp differentially expressed amplicon is marked at the bottom of the figure. 


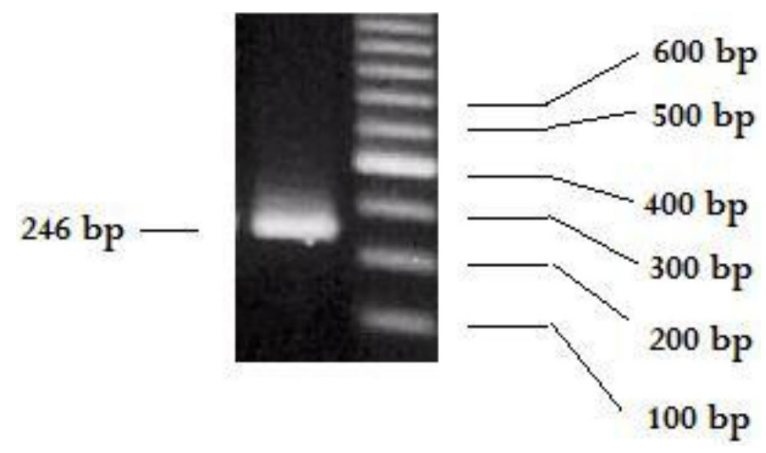

Figure 2. The 246-bp polymerase chain reaction (PCR) product generated after elution and re-amplification of the differentially expressed mRNA differential display reverse transcriptase (DDRT) amplicon originating from induced Arthrobotrys oviformis mycelium.

Northern blot analysis confirmed that the 246-bp fragment represented a gene that was expressed in A. oviformis when induced with $H$. contortus, since the target was absent in mRNA extracted from uninduced fungus (Figure 3).

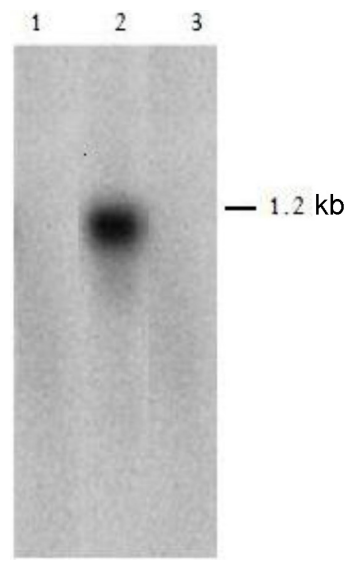

Figure 3. Northern blot RNA-DNA hybridization using total RNA isolated from uninduced and induced Arthrobotrys oviformis mycelia as target and the ${ }^{32} \mathrm{P}$-labeled 246-bp insert from the recombinant plasmid pGEMH3-2SP as the probe. Lane 1 = No template control; lane 2 = total RNA from induced A. oviformis mycelium; lane 3 = total RNA from uninduced $A$. oviformis mycelium. The 1.2-kb signal generated from lane 2 is shown with a dark line.

BLAST analysis indicates that the 246-bp sequence aligned with exon-II region of the cuticle-degrading serine protease gene (PII) reported from A. oligospora (Genbank accession No. X94121).

Multiple-sequence alignment analysis of the $A$. oviformis nucleotide (Genbank accession No. AY207006) and amino acid (Genbank accession No. AAO52730) sequences were performed using the Clustal W software (Thompson et al., 1994). Significant heterogeneity was observed at the nucleotide (Figure 4A) and amino acid levels (Figure 4B) when compared to three of its closest genetic neighbors. All three single nucleotide polymorphisms (SNPs) 

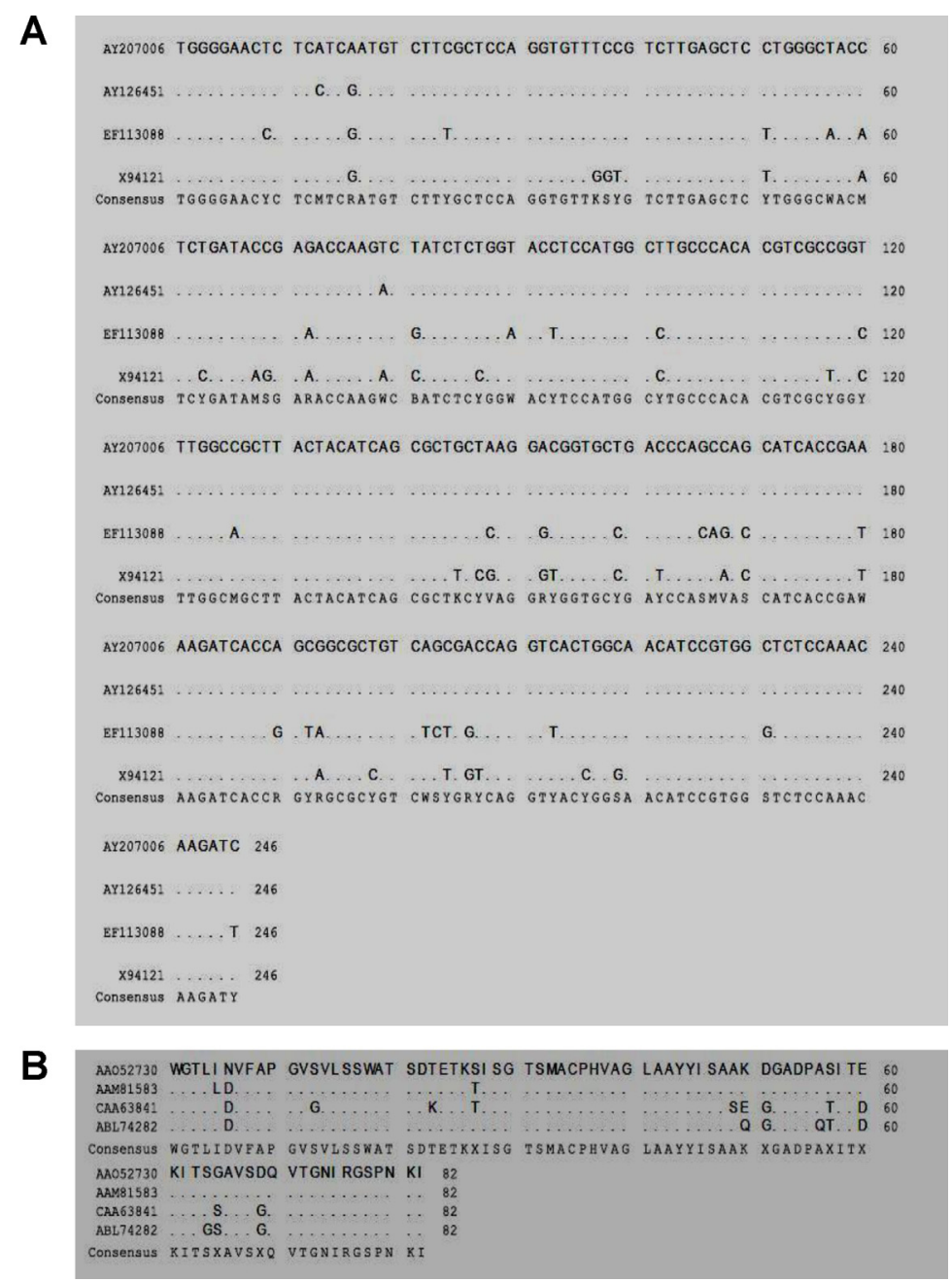

Figure 4. A. Nucleotide sequence alignment analysis of the 246-bp expressed sequence tag (EST) from exon II region of the cuticle-degrading serine protease gene (PII) from Arthrobotrys oviformis (AY207006) with the corresponding gene from Dactylaria parvispora (AY126451), A. musiformis (EF113088) and A. oligospora (X94121), respectively. Dotted lines indicate consensus sequence, and single nucleotide polymorphisms with reference to AY207006 are indicated as single-letter nucleotide codes. All bases are denoted according to IUPAC guidelines. B. Amino acid sequence alignment analysis of a stretch of 82 amino acids coded from the 24-bp EST from exon II region of the cuticle-degrading serine protease gene (PII) from A. oviformis (AAO52730) with the corresponding gene from D. parvispora (AAM81583), A. musiformis (ABL74282) and A. oligospora (CAA63841), respectively. Dotted lines indicate consensus sequence, and variant amino acids with reference to AAO52730 are indicated as single-letter amino acid codes. All amino acids are denoted according to IUPAC guidelines.

between $A$. oviformis and D. parvispora were associated with a corresponding change at the amino acid level. However, in the case of A. oligospora and A. musiformis the number of amino acid substitutions was less compared to the corresponding number of SNPs, indicating the presence of synonymous mutations (Figure 5). 


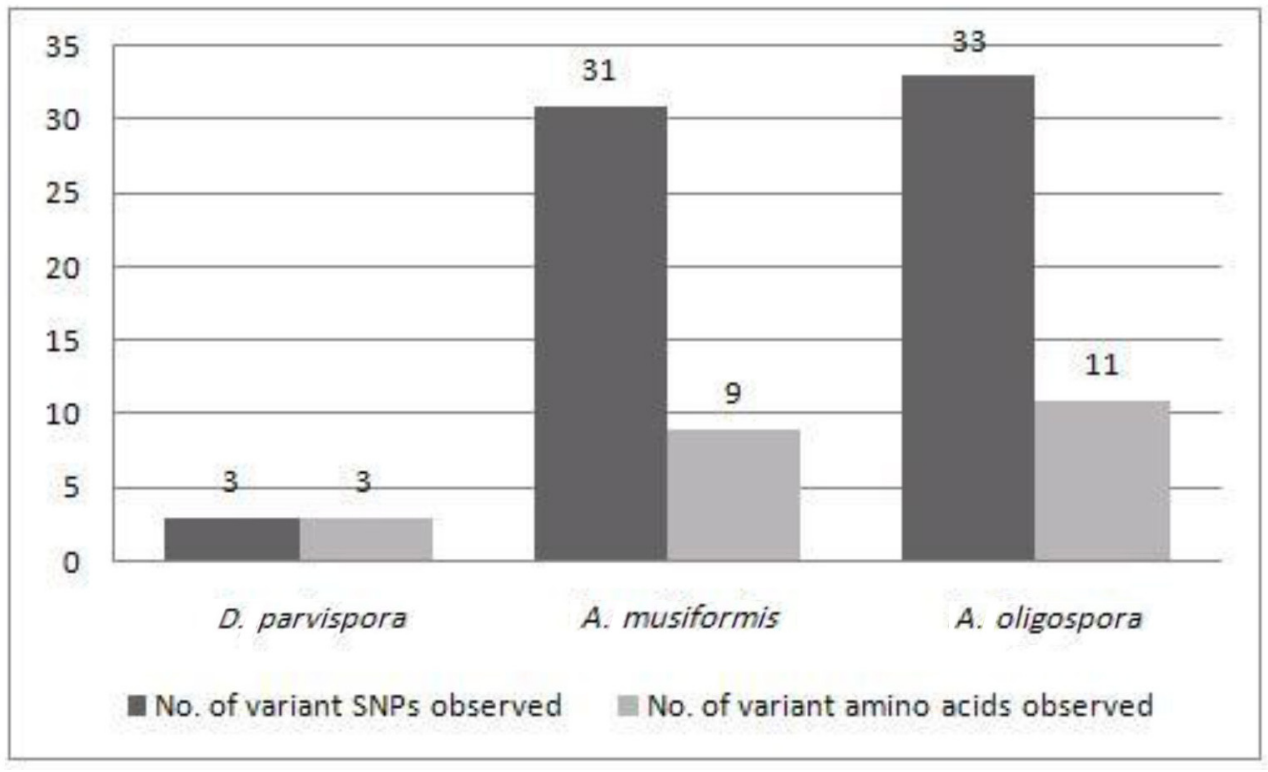

Figure 5. Graphic representation of the number of single nucleotide polymorphisms (SNPs) detected and corresponding variant of amino acids observed within the 246-bp expressed sequence tag originating from the serine protease gene of Arthrobotrys oviformis (AY207006) compared to those from Dactylaria parvispora (AY126451), A. musiformis (EF113088) and A. oligospora (X94121), respectively.

Certain SNPs are associated with alteration of amino acids within the coded protein sequence. Such variations have profound effect on gene activity. For example, in a study on the alkaline serine protease gene, VCP1 of Pochonia chlamydosporia, a biocontrol agent with commercial potential for control of root knot and cyst nematodes, it was observed that the position and nature of polymorphisms contributed significantly to host preference of the fungus (Morton et al., 2003). Therefore, there are significant efforts being made worldwide in identifying SNPs within EST originating from different economically important fungi for their exploitation in identifying genetic variants through rapid SNP detection assays (Feau et al., 2007).

In a study by Ahman et al. (2002), it has already been demonstrated that genetic engineering can be used to improve the pathogenicity of a nematode-trapping fungus. It was further envisaged that the expression of recombinant subtilisins with nematicidal activity in other organisms that are present in the habitat of parasitic nematodes (e.g., host plant) might be the future of biological control of worms.

In these contexts, the present study has significance. The EST generated from $\mathrm{A}$. oviformis and available as a DNA insert in recombinant plasmid pGEMH3-2SP can be used as a DNA-DNA hybridization probe for rapid screening of a particular variant of the serine protease gene in field isolates of nematophagous fungi. From the SNP distribution pattern, it appears that a defined set of SNPs has evolved as a distinct haplotype over time within the geographical niches of the Indian subcontinent. This makes a particular genetic variant of this gene best suited for its exploitation in generating genetically modified biological control 
fungus that is isolated from a similar region. Therefore, this study forms the basis for our long-term goal of generating a genetically modified $A$. oviformis. To our knowledge, this is the first report demonstrating the presence of differentially expressed cuticle-degrading serine protease gene in A. oviformis.

\section{ACKNOWLEDGMENTS}

The authors gratefully acknowledge the encouragement and support of Sachin Purohit in concluding and publishing the research programme.

\section{REFERENCE}

Ahman J, Ek B, Rask L and Tunlid A (1996). Sequence analysis and regulation of a gene encoding a cuticle-degrading serine protease from the nematophagous fungus Arthrobotrys oligospora. Microbiology 142 (Pt 7): 1605-1616.

Ahman J, Johansson T, Olsson M, Punt PJ, et al. (2002). Improving the pathogenicity of a nematode-trapping fungus by genetic engineering of a subtilisin with nematotoxic activity. Appl. Envir. Microbiol. 68: 3408-3415.

Barron GL (1979). Observations on predatory fungi. Can. J. Bot. 57: 187-193.

Benjamin L (2004). GENE VIII. Pearson Prentice Hall, Pearson Education, Inc., Upper Saddle River, NT 07458.

Feau N, Bergeroln MJ, Joly DL, Roussel F, et al. (2007). Detection and validation of EST-derived SNPs for poplar leaf rust Melampsora medusae f. sp. Deltoidae. Mol. Ecol. Notes 7: 1222-1228.

Gronvold J, Wolstrup J, Nansen P and Henriksen SA (1993). Nematode-trapping fungi against parasitic cattle nematodes. Parasitol. Today 9: 137-140.

Thompson JD, Higgins DG, Gibson TJ (1994). CLUSTAL W: improving the sensitivity of progressive multiple sequence alignment through sequence weighting, position-specific gap penalties and weight matrix choice. Nucleic Acids Res. 22: 4673-4680.

Liang P and Pardee AB (1992). Differential display of eukaryotic messenger RNA by means of the polymerase chain reaction. Science 257: 967-971.

Liu ZM and Kolattukudy PE (1998). Identification of a gene product induced by hard-surface contact of Colletotrichum gloeosporioides conidia as a ubiquitin-conjugating enzyme by yeast complementation. J. Bacteriol. 180: 3592-3597.

Mankau R (1980). Biological control of nematode pests by natural enemies. Annu. Rev. Phytopathol. 18: 415-440.

Minglian Z, Minghe M and Keqin Z (2004). Characterization of a neutral serine protease and its full-length cDNA from the nematode-trapping fungus Arthrobotrys oligospora. Mycologia 96: 16-22.

Morton CO, Hirsch PR, Peberdy JP and Kerry BR (2003). Cloning of and genetic variation in protease VCP1 from the nematophagous fungus Pochonia chlamydosporia. Mycol. Res. 107: 38-46.

Nagee A and Mukhopadhyaya PN (2007). Protoplast generation in the nematode trapping fungi, Arthrobotrys oviformis and Dactylaria parvispora. IJIB 1: 172-177.

Nagee A, Mukhopadhyaya PN, Sanyal PK and Kothari IL (2001). Isolation of nematode trapping fungi with potential for bio control of parasitic nematodes in animal agriculture, from ecological niches of Gujarat. INTAS POLYVET 2: 27-29.

Nagee A, Mukhopadhyaya PN, Acharya A, Aich BA, et al. (2008). A method to introduce RE recognition site within coding region of a gene without altering amino acid frame continuity. IJIB 2: 65-69.

Sambrook J, Fritsh EF and Maniatis T (1989). Molecular Cloning: A Laboratory Manual. Cold Spring Harbor Laboratory Press, New York.

Sanyal PK (1998). Integrated Parasite Management in Ruminants in India: a Concept Note. In: Biological Control of Gastro-Intestinal Nematodes of Ruminants Using Predacious Fungi. FAO Animal Production and Health Paper, Rome, 141: 54-65.

Sanyal PK and Mukhopadhyaya PN (2003). Influence of faecal dispersal time of Duddingtonia flagrans chlamydospores on larval translation of ovine Haemonchus contortus. Indian J. Anim. Sci. 73: 637-639.

Sanyal PK, Mukhopadhyaya PN and Pratap N (2002). Predatory activity and molecular signature of a new Indian isolate of Duddingtonia flagrans for use in biological control of caprine parasitic gastroenteritis. Indian J. Anim. Sci. 72: 215-219.

Tunlid A and Jansson S (1991). Proteases and their involvement in the infection and immobilization of nematodes by the nematophagous fungus Arthrobotrys oligospora. Appl. Environ. Microbiol. 57: 2868-2872. 